\title{
Corneal Endothelial Cell Density and Retinal Nerve Fiber Layer in Primary Open Angle Glaucoma, Normal Tension Glaucoma and Ocular Hypertension
}

\author{
Bakht Samar Khan ${ }^{1}$, Abid Nawaz ${ }^{2}$, Lyla Shami ${ }^{3}$, Zubaida Irshad ${ }^{4}$, Mansoor Ahmad ${ }^{5}$ \\ 1,3,5 Khyber Teaching Hospital, ${ }^{2}$ Kabir Medical College, ${ }^{4}$ Hayatabad Medical Complex, Peshawar
}

\begin{abstract}
Purpose: To compare the corneal endothelial cell density (CED) and retinal nerve fiber layer thickness (RNFL) in primary open angle glaucoma (POAG), normal tension glaucoma (NTG) and ocular hypertension (OHT).

Study Design: Cross sectional Observational study.

Place and Duration of Study: Khyber Teaching Hospital, Peshawar, from April 2016 to March 2018.

Methods: Patients having a single IOP reading of $21 \mathrm{~mm} \mathrm{Hg}$ or more with glaucomatous cupping, visual field defect and open angle were labeled as POAG. Patients with IOP less than $21 \mathrm{~mm} \mathrm{Hg}$ with same findings were labeled as NTG. Those eyes with raised IOP (more than $21 \mathrm{~mm} \mathrm{Hg}$ ), normal visual field and optic disc were labeled as OHT. Corneal endothelial cell count, central corneal thickness and retinal nerve fiber layer (RNFL) thickness were measured in patients of POAG, NTG and OHT. These were compared with normal age matched values.
\end{abstract}

Results: Thirty eyes with POAG, 10 with $\mathrm{OHT}$ and 10 with NTG were included in the study. In patients with POAG there was $13.33 \%$ CED and $27.7 \%$ mean RNFL thickness loss. In patients with NTG there was $3.06 \%$ CED and $34.04 \%$ mean RNFL thickness loss. In patients with OHT there was $7.17 \%$ CED and $5.5 \%$ mean RNFL thickness loss.

Conclusion: The loss of both RNFL thickness and CED occurs in POAG, OHT and NTG. Severe loss of RNFL thickness occurs in POAG and NTG while severe loss of CED occurs in POAG and OHT. Mild loss of RNFL thickness occurs in OHT while mild loss of CED occurs in NTG.

Key Words: Specular Microscopy, Optical Coherence Tomography, Nerve Fiber Layer, Open Angle Glaucoma, Ocular Hypertension.

How to Cite this Article: Khan BS, Nawaz A, Shami L, Irshad Z, Ahmad M. Corneal Endothelial Cell Density and Retinal Nerve Fiber Layer in Primary Open Angle Glaucoma, Normal Tension Glaucoma and Ocular Hypertension. Pak J Ophthalmol. 2021, 37 (1): 43-47.

Doi: https://doi.org/10.36351/pjo.v37i1.1062

Correspondence: Bakht Samar Khan

Department of Ophthalmology

Khyber Teaching Hospital

Peshawar

Email: bestbakht@yahoo.com

Received: May 4, 2020

Accepted: August 19, 2020

\section{INTRODUCTION}

Glaucoma is a progressive optic neuropathy associated with transient or permanent rise of IOP leading to visual field defects or even blindness. Glaucoma is a multi-factorial disease in which there is progressive degeneration of retinal ganglion cells along with their axons. The proposed theories of glaucomatous damage are ischemic, mechanical and neurotoxin related. Glaucomatous optic neuropathy with physiological IOP was labeled as low tension glaucoma (LTG) by 
Voncraft in $19^{\text {th }}$ century. ${ }^{1}$ Within the spectrum of POAG, a physiological IOP has been classified as normal tension glaucoma (NTG), or low tension glaucoma (LTG). ${ }^{2,3}$ NTG is the most accurate terminology used for these types of glaucoma. OCT and scanning laser modalities have confirmed thinning of the peri-papillary choroid as well as thinning of ganglion cell layer in NTG as compared to normal eyes. ${ }^{4,5}$

The term ocular hypertension (OHT) was used by Chandler PA and Drance in 1962. This was defined by Perkins and others in 1966 as a condition with the following criteria; ${ }^{6}$ IOP greater than $21 \mathrm{~mm} \mathrm{Hg}$ on two or more occasions, normal VF, optic disc and RNFL, normal open angle, absence of ocular conditions contributing to a rise in the IOP e.g. uveitis and neovascular conditions. The terms ocular hypertension, glaucoma suspect and pre-glaucoma were used by Jhonson TD and Zimmerman TJ. ${ }^{7}$

Whatever is the mechanism of glaucoma, its effects will be on all ocular tissues especially on corneal endothelium, optic nerve head and retinal nerve fiber layer.

Normally $0.6 \%$ of corneal endothelial cell density is lost per year from age 15 years onwards. ${ }^{8}$ Normal endothelial cell count in the sub-continent population is $2408 \pm 274 \mathrm{cell} / \mathrm{mm}^{2}$, while in Japanese it is $3749 \pm$ $407 \mathrm{cell} / \mathrm{mm}^{2}$ at the age of 40 years and above. With Specular microscope, the examination of corneal endothelial cell density is possible in detail. At birth, the endothelial cell count is between 4000-5000 cells $/ \mathrm{mm}^{2}$. With age there is a decline in the cell count; at the age of 40 and above it comes down to 20003000 cells $/ \mathrm{mm}^{2}$. Endothelial cell count below 500 cells $/ \mathrm{mm}^{2}$ poses a risk for corneal endothelial dysfunction. ${ }^{8}$

In Glaucoma, the corneal endothelial cell density (CED) is affected directly by the high IOP or by congenital anomaly of endothelium or by antiglaucoma medication toxicity. ${ }^{9,10}$ There are anatomical and functional changes. The anatomical changes appear before the functional changes. Early diagnosis relies on detecting the anatomical changes. The analysis of these structural changes is facilitated by color fundus images and optical coherence tomography (OCT). These give us qualitative and quantitative information about optic nerve and RNFL in Glaucoma. ${ }^{11}$

A normal non-glaucomatous eye has RNFL thickness of 80 microns or greater, whereas 70-79 microns thickness of RNLF is suspicious while 60-69 microns thickness is glaucomatous in $95 \%$ of cases. Normally the neuro retinal rim of optic nerve head is comparatively thickest inferiorly and thinnest temporally. When the optic nerve does not follow this rule, it may have glaucomatous damage ${ }^{12}$ but it may not be very effective in detection of early glaucoma. ${ }^{13}$

The aim of this study was to find the relationship between loss of corneal endothelium and retinal nerve fiber layer in open angle glaucoma, normal tension glaucoma and ocular hypertension.

\section{METHODS}

This prospective study included 50 eyes, 30 with POAG, 10 eyes with NTG and 10 eyes diagnosed with OHT. We used specular microscopy to find out the corneal endothelial status. To determine the thickness of RNFL, OCT was performed. The results were compared with normal age-matched database.

Specular microscopy was performed to see status of corneal endothelial cells with non-contact instrument (Konan Medical, Hyogo, Japan). Several photographs were taken and only clear ones were selected for interpretation of CED. Endothelial cells were analyzed by the dot method, in which the sites of approximately $30-80$ contiguous cells were marked. Ultrasonic pachymetry was performed for central corneal thickness. IOP phasing was done at 6 hour intervals with Goldman applanation tonometer. A single IOP reading of $21 \mathrm{~mm} \mathrm{Hg}$ or more with glaucomatous cupping, visual field defect and open angle were labeled as POAG. Patients with IOP of $21 \mathrm{~mm} \mathrm{Hg}$ or less, with glaucomatous cupping, visual field defect and open angle were labeled as NTG. The eyes with raised IOP (more than $21 \mathrm{~mm} \mathrm{Hg}$ ), normal visual field and optic disc were labeled as OHT. OCT of optic disc and RNFL were performed on all patients. The findings were compared with normal age-matched controls (Table 1). 
Table 1: Specular microscopy and OCT findings.

\begin{tabular}{|c|c|c|c|c|c|c|}
\hline & \multicolumn{3}{|c|}{$\begin{array}{c}\text { Specular Microscopy } \\
\text { Mean Corneal Endothelial Cell Count (cells } / \mathrm{mm}^{2} \text { ) }\end{array}$} & \multicolumn{3}{|c|}{ Mean RNFL Thickness (OCT) (in $\mu \mathrm{m}$ ) } \\
\hline & Patients & $\begin{array}{l}\text { Normal Data } \\
\text { Base }\end{array}$ & Loss \%age & Patients & $\begin{array}{l}\text { Normal Data } \\
\text { Base }\end{array}$ & Loss \%age \\
\hline Open Angle Glaucoma & $2320(\mathrm{n}=30)$ & 2677 & $13.33 \%$ & $65(\mathrm{n}=30)$ & 90 & $27.7 \%$ \\
\hline Normal Tension Glaucoma & $2595(\mathrm{n}=10)$ & 2677 & $3.06 \%$ & $59(\mathrm{n}=10)$ & 90 & $34.4 \%$ \\
\hline Ocular Hypertension & $2485(n=10)$ & 2677 & $7.17 \%$ & $85(\mathrm{n}=10)$ & 90 & $5.5 \%$ \\
\hline
\end{tabular}

\section{DISCUSSION}

The two important non regenerative structures in eye are corneal endothelium (CE) and RNFL. Corneal endothelial cell loss and decreased RNFL has been reported by raised IOP in POAG and OHT. Several studies have been conducted employing specular microscopy to examine the CED separately in either POAG or OHT or NTG. No reliable study was found to have examined CED and retinal nerve fiber layer (RNFL) loss in POAG, OHT and NTG together.

Association of Corneal endothelial cell loss with POAG, NTG and OHT has been reported in literature. ${ }^{9}$ Other studies have also reported lower CED in NTG eyes. ${ }^{10}$ The association between raised IOP and endothelial cell loss has been reported by Cho SW et $\mathrm{al},{ }^{14}$ where the mean CED was $2696.7 \pm 303.9$ cells $/ \mathrm{mm}^{2}$ in NTG, $2370.5 \pm 392.3$ cells $/ \mathrm{mm}^{2}$ in POAG and $2723.6 \pm 300.6$ cells $/ \mathrm{mm}^{2}$ in the normal age matched population. While this shows a significantly lower CED in eyes with POAG than in NTG, it also indicates a loss of CED in NTG as compared to the normal group. In our study the CED was 2595 cells $/ \mathrm{mm}^{2}$ in NTG as compared to 2677 cells $/ \mathrm{mm}^{2}$ in the normal age group. This shows a loss of $3.06 \%$. Similar results were reported in other studies. ${ }^{15,16}$

In NTG/LTG, optic neuropathy and endothelial cell loss or damage has been reported by Lee et al. In their study the endothelial cell count was significantly lower in NTG vs POAG $(2380 \pm 315.4$ vs $2530 \pm$ 320.4). ${ }^{17}$ Changes and decrease in corneal endothelial cell density in POAG have been reported in other studies. ${ }^{18,19}$ Knorr et al. reported a $31 \%$ reduction of CED in POAG. ${ }^{20}$

Urban et al in their study found that the CED was significantly lower in eyes with POAG, being 2639.5 cells $/ \mathrm{mm}^{2}$ as compared with 2924.5 cells $/ \mathrm{mm}^{2}$ in OHT and 2955 cells $/ \mathrm{mm}^{2}$ in the control group. ${ }^{21}$ In the study of Prasannakumary et al, the mean CED in POAG patients was significantly lower $(2211.13 \pm 171.49$ cells $/ \mathrm{mm}^{2}$ in right eye, $2198.20 \pm 154.39 \mathrm{cells} / \mathrm{mm}^{2}$ in left eye) compared to control group (2417.43 \pm 116.92 in right eye and $2390.18 \pm 101.31$ cells $/ \mathrm{mm} 2$ in left eye). ${ }^{22}$ This study is similar to our POAG findings. All these studies confirm the loss of CED in POAG and OHT. The hypothesis for corneal endothelial damage in glaucoma and ocular hypertension is that it is brought about by elevated IOP and medication induced toxicity. ${ }^{22}$

As far as loss of thickness of RNFL is concerned, it has been reported with raised IOP. Interestingly thin RNFL has been reported in ocular hypertensive eyes with thinner corneas, whereas ocular hypertensive eyes with thick and normal cornea had normal nerve fiber layer thickness. ${ }^{16}$ Asymmetry in intra ocular pressure in the two eyes of the same patients with NTG resulted in more thinning of the RNFL in eyes with the higher IOP.

In the study by Tarek et al the mean RNFL thickness was $97.2 \pm 9.24$ um in healthy subjects, while it was thinner being $60.2 \pm 15.9$ um in POAG eyes. $^{23}$ This is comparable to our study where it was 65 um in POAG. In the study of Gyatsho at et al, OCT detected RNFL thickness differences in POAG, OHT and normal age matched controls. The findings were thinner RNFL in OHT eyes than normal while thinner RNFL in POAG eyes than OHT eyes. ${ }^{24}$

In a study by Christopher et al, the mean RNFL thickness was $72.8 \mathrm{um}$ in OHT eyes compared to normal eyes, which was $85 \mathrm{um}$. This observation shows thinner RNFL in OHT eyes. Further findings of his study were that RNFL was thinner in the inferior quadrant, 84.8 um versus $107.6 \mathrm{um}$, while in the nasal quadrant it was 44 um versus 61.8 um respectively. In the same study, RNFL thickness was less in glaucomatous eyes than in OHT and normal eyes in all quadrants. ${ }^{25}$ In our study the mean RNFL thickness in OHT was 85 um compared with 90 um in the normal eyes.

Many studies including our study confirm the loss of RNFL thickness in open angle glaucoma and OHT. Based on the findings of this study our observation is 
that in POAG, OHT and in NTG both the vital tissues i.e., the corneal endothelium and the nerve fiber layer are affected. The mechanism may be raised IOP, ischemia and toxins in ocular fluids.

Limitation of this study was small sample size. Large population and multiple centered studies are needed to get a complete picture of these characteristics in a particular region.

\section{CONCLUSION}

The loss of both RNFL thickness and CED occurs in POAG, OHT and NTG. Severe loss of RNFL thickness occurs in POAG and NTG while severe loss of CED occurs in POAG and OHT. Mild loss of RNFL thickness occurs in OHT while mild loss of CED occurs in NTG.

\section{Ethical Approval}

The study was approved by the Institutional review board/ Ethical review board. (994/ADR/KMC)

\section{Conflict of Interest}

Authors declared no conflict of interest.

\section{REFERENCES}

1. Lee BL, Bathija RNW. The definition of normal tension glaucoma. J Glaucoma. 1998; 7 (6): 366-371.

2. Levene RZ. Low tension glaucoma part II clinical characteristic and pathogenesis Ann Ophthalmol. 1980; 12 (12): 1383.

3. Trivli A, Koliarakis I, Terzidou C, Goulielmos GN, Siganos CS, Spandidos DA, et al. Normal-tension glaucoma: Pathogenesis and genetics (Review). Exp Ther Med. 2019; 17 (1): 563-574. https://doi.org/10.3892/etm.2018.7011

4. Hirooka K, Tenkumo K, Fujiwara A, Baba T, Sato S, Shiraga F. Evaluation of peripapillary choridal thickness in patients with NTG BMC Ophthalmol. 2012; 12: 29.

5. Firat PG, Ozsoy E, Demirel S, Cumurcu T, Gunduz A. Evaluation of peripapillary retinal nerve fiber layer, macula and ganglion cell thickness in amblyopia using spectral optical coherence tomography. Int $\mathbf{J}$ Ophthalmol. 2013; 6 (1): 90-94.

doi.org/10.3980/j.issn.2222-3959.2013.01.19

6. Chandler PA, Grant WM. Ocular Hypertension VS Open Angle Glaucoma. Arch. Ophthalmol. 1977; 95 (4): 585-586.
7. Jhonson TD, Zimmerman T. Ocular hypertension, glaucoma suspect, preglaucoma or glaucoma. Synopsis of view. Ann Ophthalmol. 1986; 18 (11): 313-314.

8. Celebi ARC, Mirza GE. Age related change in retinal nerve fiber layer thickness measured with spectral domain optical coherence tomography. Invest Ophthalmol Vis Sci. 2013; 54: 8095-8103.

9. Gagnon MM, Boisjoly HM, Brunette I, Charest M, Amyot M. Corneal endothelial cell density in glaucoma. Cornea. 1997; 16: 314-318.

10. Higa A, Sakai H, Sawaguchis S, Iwase A, Tomidokoro A, Amano S, et al. Corneal endothelial cell density and associated factor in a population study in Japan: the kumejama study. Am J Ophthalmol. 2010; 149: 794-799.

11. Badala F, Nouri-Mahdavi K, Reoof DA, Lew SK, Caprioli S. Optic disc and NFL imaging to detect glaucoma. Am J Ophthalmol. 2007; 144 (5): 724-732

12. Chan EW, Liao Jiemin, Wong R, Luon SC, Aung T, Wong TY, et al. Diagnostic performance of the ISNT rule for glaucoma based on the Heidelberg retinal tomograph. Transl Visc Sci Technol. 2013; 2 (5): 2.

13. Moon J, Park KH, Kim DM, Kim SH. Factors affecting ISNT Rule satisfaction in normal and glaucomatous eyes. Korean J Ophthalmol 2018; 32 (1): 38-44.

14. Cho SW, Kim JM, Choicy, Parl KH. Change in corneal endothelial cell density in patients with NTC JPN. Ophthalmol. 2009; 53: 569-573.

15. Gugleta K, Flammer J. Asymmetry in intraocular pressure and retinal nerve fiber layer thickness in normal tension glaucoma. Ophthalmologica. 1999; 213 (4): 219-223.

16. Henderson PA, Medeiros FA, Zangwill LM, Weinreb RN. Relationship between central corneal thickness and RNL thickness in ocular hypertension patients. Ophthalmology, 2005; 112 (2): 251-256.

17. Lee JWY, Wong RLM, Chan JCH, Wong IYH, Lai JM. Differences in corneal parameters between normal tension glaucoma and primary open angle glaucoma. Int Ophthalmol. 2015; 35 (I): 67-72.

18. Sihota R, Lakshmaiah C, Titiyal JS, Dada T, Agarwal HC. Corneal endothelial status in the subtypes of primary angle closure glaucoma. Clin Exp Ophthalmol. 2003; 31: 492-495.

19. Korey M, Gieser D, Kass MA, Waltman SR, Gordon M, Becker B. Central corneal endothelial cell density and central corneal thickness in ocular hypertension and primary open-angle glaucoma. Am J Ophthalmol. 1982; 94: 610-616.

20. Knorr HL, Händel A, Naumann GO. Morphometric and qualitative changes in corneal endothelium in primary chronic open angle glaucoma. Fortschr Ophthalmol. 1991; 88: 118-120. 
21. Urban B, Bakunowicz-Lazarczyk A, Michalczuk M, Krętowska M. Evaluation of corneal endothelium in adolescents with juvenile glaucoma. J Ophthalmol. 2015; 2015: 895428.

22. Prasannakumary C, Ragi TK, Raju KV. Corneal Endothelial Cell Changes in POAG \& Its Relation with Severity of Field Defect. JMed Sci Clin Res. 2017; 5 (5): 22339-22343.

23. Tarek A, Kaidi W, Fei Y, Field MG, Lee H, Baniasadi N, et al. Correlation of retinal nerve fiber layer thickness and VF in glaucoma. A broken stick model. AM J Ophthalmol. 2014; 157 (5): 953-959.

24. Gyatsho J, Kaushik S, Gupta A, Pandav SS, Ram J. Retinal NFL thickness is normal, ocular hypertensive and glaucomatous in Indian eyes. An optical coharent tomography study. J Glaucoma. 2008; 17 (2): 122-127.

25. Christopher B, Robert NW, Julia MW. The RNFL thickness in $\mathrm{OH}$, normal and glaucomatous eye with OCT. Arch Ophthalmol. 2000; 118 (1): 22-26.

\section{Authors' Designation and Contribution}

Bakht Samar Khan; Associate Professor: Concepts, Design, Literature search, Data acquisition, Data analysis, Statistical analysis, Manuscript preparation.

Abid Nawaz; Literature search, Data analysis, Statistical analysis, Manuscript review.

Lyla Shamim; Medical Officer: Literature search, Data acquisition.

Zubaida Irshad; Assistant Professor: Literature search, Data acquisition, Data analysis, Statistical analysis, Manuscript preparation, Manuscript editing.

Mansoor Ahmad; Senior House Officer: Literature search, Data acquisition, Manuscript editing. 